\title{
BMJ Open Incidence of childhood injuries and modifiable household risk factors in rural Ghana: a multistage, cluster- randomised, population-based, household survey
}

To cite: Gyedu A, Stewart BT, Otupiri E, et al. Incidence of childhood injuries and modifiable household risk factors in rural Ghana: a multistage, clusterrandomised, population-based, household survey. BMJ Open 2021;11:e039243. doi:10.1136/ bmjopen-2020-039243

- Prepublication history for this paper is available online. To view these files, please visit the journal online (http://dx.doi. org/10.1136/bmjopen-2020039243).

$A G$ and $B T S$ are joint first authors.

Received 27 January 202 Accepted 11 June 2021

Check for updates

(c) Author(s) (or their employer(s)) 2021. Re-use permitted under CC BY-NC. No commercial re-use. See rights and permissions. Published by BMJ.

For numbered affiliations see end of article.

Correspondence to Dr Barclay T Stewart; barclays@uw.edu

\section{ABSTRACT}

Objective We aimed to describe the incidence of childhood household injuries and prevalence of modifiable household risk factors in rural Ghana to inform prevention initiatives.

Setting 357 randomly selected households in rural Ghana. Participants Caregivers of children aged $<5$ years. Primary and secondary outcome measures Childhood injuries that occurred within 6 months and 200 metres of the home that resulted in missed school/work, hospitalisation and/or death. Sampling weights were applied, injuries were described and multilevel regression was used to identify risk factors.

Results Caregivers from 357 households had a mean age of 35 years (SD 12.8) and often supervised $\geq 2$ children (51\%). Households typically used biomass fuels (84\%) on a cookstove outside the home $(79 \%)$. Cookstoves were commonly $<1$ metre of the ground $(95 \%)$. Weighted incidence of childhood injury was 542 per 1000 childyears. Falls (37\%), lacerations (24\%), burns $(12 \%)$ and violence $(12 \%)$ were common mechanisms. There were differences in mechanism across age groups $(p<0.01)$, but no gender differences $(p=0.25)$. Presence of older children in the home $(\mathrm{OR} 0.15,95 \% \mathrm{Cl} 0.09$ to 0.24 ; adjusted $0 \mathrm{R}$ (aOR) $0.26,95 \% \mathrm{Cl} 0.13$ to 0.54 ) and cooking outside the home (OR $0.28,95 \% \mathrm{Cl} 0.19$ to 0.42 ; aOR $0.25,95 \% \mathrm{Cl}$ 0.13 to 0.49 ) were protective against injury, but other common modifiable risk factors (eg, stove height, fuel type, secured cabinets) were not.

Conclusions Childhood injuries occurred frequently in rural Ghana. Several common modifiable household risk factors were not associated with an increase in household injuries. Presence of older children was a protective factor, suggesting that efforts to improve supervision of younger children might be effective prevention strategies.

\section{INTRODUCTION}

Injury is a leading cause of preventable death and disability globally, particularly among children. ${ }^{1}$ Injuries account for one in seven toddler-aged child deaths and are the most common cause of death among adolescents
Strengths and limitations of this study

- The study used a cluster-randomised, populationbased survey, which is a more robust design for determining incidence than hospital-based registries.

- There was potential for recall bias given questions about potentially temporally remote childhood injuries, although we did not ask about injuries more than 6 months prior.

- There was also potential for social response bias given questions about socioeconomic status, supervision and exposure to specific hazards.

and teenagers worldwide. ${ }^{12}$ However, death represents only the tip of the iceberg; injuries more commonly result in short-term or longterm physical and psychosocial disability, missed days of school and social activities and stress within households. ${ }^{3}$ The impacts of injury are disproportionately experienced by children, families and communities in low-income and middle-income countries (LMICs). The reasons for this are several and include insufficient number and reach of prevention initiatives, poor access to organised trauma care and lack of availability of multidisciplinary rehabilitation and community reintegration programmes. ${ }^{24-6}$

The most common location of childhood injuries are in or around the home regardless of national income. ${ }^{3} 7$ As a result, multisectoral stakeholders in high-income countries have collaborated on a number of injury prevention initiatives that target household injuries (eg, childproofing cabinets, thermoregulation of hot water heaters, smoke detectors, boundary gates, traffic calming) based on convincing epidemiological data from injury surveillance activities. Given the lack of analogous injury surveillance activities 
and epidemiological data in LMICs, there is insufficient evidence to inform prevention initiatives or guidelines where they are most needed. ${ }^{238-11}$

Hospital-based and population-based surveillance data on injuries are rare, particularly in sub-Saharan Africa where childhood injuries are thought to be particularly common. ${ }^{12-14}$ There are only several population-based studies of injuries in sub-Saharan Africa, and none focus on rural injuries, which likely have significantly different epidemiology and risk factors than injuries sustained by children in urban settings, including from Ghana. ${ }^{15-18}$ As example, a cluster-randomised, household survey of injuries in urban Ghana found that the incidence of childhood injuries was 10 times higher in Ghana than it was in the USA. ${ }^{17}$ This report is the only one from Ghana that has described childhood injuries that occurred in or around the home, which is known to be the location of most childhood injuries globally. ${ }^{210} 19$ Given the urgent need for progress to be made in the prevention of childhood injuries in sub-Saharan Africa, more work is required to identify injury hazards in the household environment.

Therefore, we aimed to determine the incidence of childhood household injuries in rural Ghana and characterise modifiable household risk factors in an effort to identify prevention targets.

\section{METHODS}

\section{Setting}

Ghana is a lower-middle income country in West Africa that sits on the Atlantic Ocean and borders Togo, Cote d'Ivoire and Burkina Faso. ${ }^{20}$ Approximately $45 \%$ of Ghanaians live in rural communities. ${ }^{20}$ Many rural communities are proximate to more populated areas with some health resources (eg, health promotion initiatives, organised prehospital care services, referral and tertiary hospitals), but there are fewer health initiatives and poorer access to healthcare services in rural areas. As in other LMICs, rural communities in Ghana that are adjacent to more populated areas are often home to particularly marginalised people who work in very low-wage jobs within the adjacent urban area, agriculture or pastoralism or practice subsistence activities.

\section{Patient and public involvement}

Participants were not involved in the development of the research question, study design, outcome measures or recruitment. Community members and study assistants conducted the household surveys. Dissemination to community members will occur via Kwame Nkrumah University of Science and Technology public health outreach initiatives and local media.

\section{Design and sample strategy}

We designed a nested, multistage, cluster-randomised, population-based, survey to examine the incidence of household injuries and associated risk factors in rural communities adjacent to a large metropolis. The current study was nested within a larger study of households with children under age 5 years. However, a specific sampling strategy was used based on known injury epidemiology in Ghana. ${ }^{21}$ Using an injury rate of $29.7 \%$ over 6 months reported by Gyedu et al, a 95\% CI and a margin of error of $10 \%$, a sample size of 314 was calculated. We chose 364 to allow for non-consenting households or incomplete entries. First, computer random sampling was used to select one rural district (ie, population density $\leq 500$ people per square kilometre) that borders the Kumasi metropolis in Ashanti Region, Ghana (strata 1). Four districts were eligible (Kwabre, Ejisu Juaben, Bosomtwe and Atwima). Bosomtwe district was selected. Second, computer random sampling was used to select one of three subdistricts (ie, Amakom, Kuntanase and Jachi-Pramso), which were similar in demography and socioeconomic status according to data from the most recent census in 2010 published in 2014 (strata 2).$^{22}$ Amakom was selected. Third, 6 community clusters were randomly sampled from a list of 11 community clusters in Amakom provided by the Ghana Statistical Service (strata 3). Within each cluster, we exhaustively sampled each dwelling. Dwellings often were the home of multiple households. Within each dwelling, we asked the heads of household if there was a child aged $<5$ years. Only households with a child aged $<5$ years were eligible to participate in the survey; however, households with a child aged $<5$ years and older children were also sampled. Lastly, field computer random sampling was used to select one eligible household within each dwelling (strata 4). The sample reflects the population of Amakom (18988 people of which 3779 were aged $<5$ years and 14032 were aged $<18$ years $){ }^{22}$

\section{Survey tool and technique}

In each household, one adult household member (ie, sleeps in the home most nights and over age 18 years) who self-identified as the primary caregiver for at least one child aged $<5$ years on a daily basis was selected to undergo informed consent. Consenting respondents participated in the survey. Only one caregiver was sampled per eligible household. Caregivers were interviewed using a previously validated structured questionnaire about household characteristics and modifiable risk factors for childhood injuries. ${ }^{17}$ Items in the survey were selected from the 2008 Ghana Demographic and Health Survey and were previously identified through household-based surveys of childhood injury. ${ }^{72} 24$ The survey was administered by local enumerators in Twi, the predominant language spoken in southern and central Ghana.

The same definition of household injury used to understand urban childhood injuries was used, and defined as $^{17}$ :

1. Occurred within 200 metres of the house;

2. Prevented the child from going to school or work, prompted healthcare treatment or resulted in death; and

3. Occurred within the previous 6 months. 
Recall periods of 1-3months and 1year have been proposed for surveys of less severe and more severe/ fatal injuries in LMICs to mitigate recall bias, respectively. We used a recall period of 6 months to capture both moderate and severe injuries. We used the injury severity classification proposed by the UNICEF Innocenti Research Centre ${ }^{25}$ :

1. Moderate-missed $\geq 1$ day of school or work or sought healthcare without being hospitalised,

2. Major-hospitalised for 1-9 days,

3. Serious-hospitalised for $10+$ days,

4. Severe-resulted in permanent disability, or

5. Fatal-resulted in death.

\section{Data management and analysis}

Data were collected by the enumerators and transcribed into the Open Data Kit platform. Enumerators collected demographic and household characteristics, including information regarding ownership of consumable goods and physical characteristics of the household, which were used to construct a wealth index using principal component analysis (PCA) in accordance with the methodology used by the Ghana Statistical Service. ${ }^{17}$ Scores generated by the PCA were divided into socioeconomic quintiles. Injury epidemiology and household risk factors were described. Analyses incorporated sampling weights, which reflected the probability of being randomly sampled at the community cluster (strata 3) and household levels (strata 4). The results were weighted to be representative of Amakom subdistrict.

Multiple injuries sustained by a child were counted once for each mechanism of injury and separately for different mechanisms. Incidence and risk factors were compared with Mann-Whitney $\mathrm{U}$ and $\chi^{2}$ tests, as appropriate. The primary outcome variable was occurrence of at least moderate injury in a child aged $<18$ years. We performed univariate logistic regression to assess the relationship between risk factors and injury occurrence. Multivariate, multilevel (ie, community cluster, household) logistic regression models incorporated covariates independently significant in the univariate analysis ( $\mathrm{p}$ value $\leq 0.05$ ) as well as variables that were felt to be important or confounding (eg, age and sex of the child, caregiver level of education). Multicollinearity among covariates was assessed with tolerance and variance inflation factors. Collinear covariates were excluded. The model was then assessed after adjusting for other non-significant, but potentially important, risk factors using backward elimination. The fitted model was assessed using Hosmer and Lemeshow's goodness-of-fit test $(\mathrm{p} \leq 0.10)$ and Akaike information criterion. Secondary multivariate regression models were performed for the subset of children aged $<5$ years.

\section{RESULTS}

Households

We sampled 357 households that represented 2713 households in Amakom. Most households were owned and completed structures ( $72 \%$ of households) with one to two sleeping rooms $(74 \%)$ (table 1 ). Households typically cooked with biomass fuels (eg, wood, plant material, dung; $86 \%$ of households) outside of the house (88\%). The vast majority of cookstoves were positioned within reach of a child aged $<5$ years (ie, $<1$ metre of the ground; $96 \%$ of households). Similarly, $85 \%$ of households did not have safe cabinets to store hazardous substances from children (eg, medications, fertiliser, cleaning liquid).

\section{Caregivers}

The mean caregiver age was 33 years (SD 18.5 years) (table 2). Most caregivers were biological mothers of the children (79\% of caregivers) with no or only primary school education (92\%) and engaged in intermittent hourly employment $(69 \%)$. Almost half of caregivers supervised three or more children (47\% of caregivers). Only $6 \%$ of caregivers were exposed to a formal first aid training programme (eg, taught at school, church, mosque; taught by community health aide or Ghana Red Cross Society).

\section{Children and injuries}

There were 1016 children in our sampled household population (492 children aged $<5$ years) that represented 14032 total children in Amakom (3779 children aged $<5$ years). The mean age of children was 6.6 years (SD 4 years) and about half were male (52\%) (table 2). There were 351 moderate or more severe injuries in our sample, which equated to an annualised incidence of 542 injuries per 1000 child-years (table 3). Falls (37\% of injuries; 211 per 1000 child-years), lacerations (24\%; 126 per 1000 child-years), violence (12\%; 68 per 1000 childyears) and burns (12\%; 63 per 1000 child-years) were the most common injury mechanisms. There were significant differences in injury mechanism across childhood age groups (46\% of all injuries occurred among ages 1-4 years; $p<0.01)$. As example, injuries from falls, burns and violence were significantly more common among infants (children aged $<1$ year) and toddlers (ages $1-4$ years) than older age groups $(\mathrm{p} \leq 0.01$ for all). However, lacerations and motor vehicle-related injuries were more common in older age groups $(\mathrm{p}=0.01$ and $\mathrm{p}=0.11$, respectively $)$. No significant gender differences were identified (table 4). Most injuries were moderate in severity (ie, missed $\geq 1$ day of school or work or sought healthcare without being hospitalised; $82 \%$ of injuries) (table 2). About $15 \%$ of injuries resulted in hospitalisation and $1 \%$ of children who sustained an injury died.

\section{Risk factors}

In the univariate models for injuries among children aged $<18$ years, older caregiver age (OR 0.99, 95\% CI 0.98 to 1 ), more advanced caregiver education (eg, senior high school education OR 1.79, 95\% CI 1.01 to 3.18; no education is reference), greater number of older children under supervision (eg, three older children in the household OR $0.26,95 \%$ CI 0.17 to 0.41 ; one older child 
Table 1 Rural household characteristics in Amakom subdistrict, Ghana

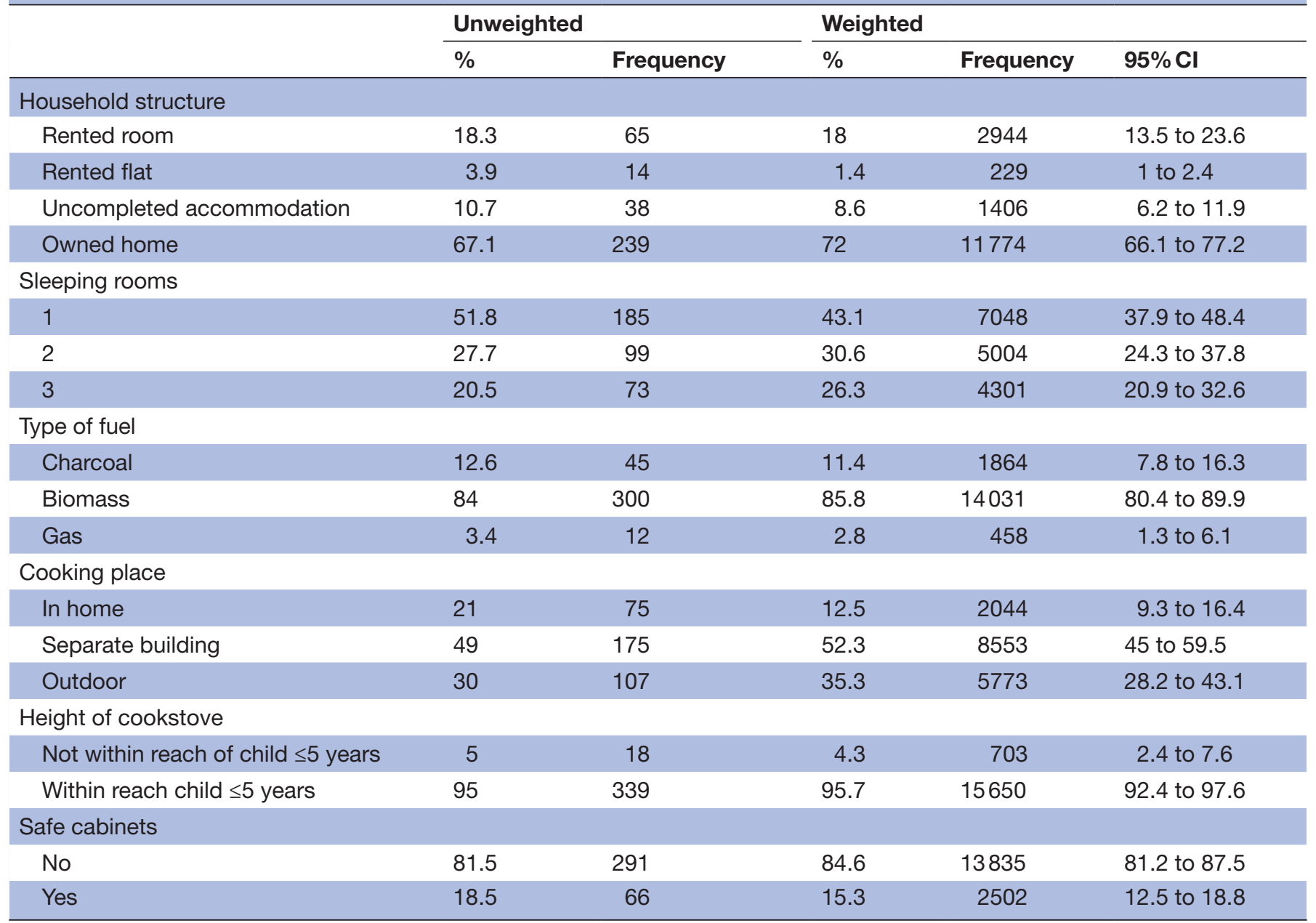

is reference), cooking outside of the home (OR 0.43, $95 \%$ CI 0.29 to 0.63 ) and living in a home with multiple sleeping rooms were protective against injury (OR 0.55 , $95 \%$ CI 0.37 to 0.81 ) (table 5). The multivariate model determined that having older children in the home (eg, three older children in the household OR $0.38,95 \%$ CI 0.22 to 0.65 ; one older child is reference), being in higher socioeconomic quintiles (OR 1.14, 95\% CI 1.02 to 1.27 ), cooking outside (OR $0.54,95 \%$ CI 0.33 to 0.88 ) and living in completed housing were protective against injury (eg, living in uncompleted housing OR 1.72, 95\% CI 1 to 3.01; living in rented room is reference). Importantly, there was no association with several potentially modifiable risk factors, including type of cookstove fuel used, height of cookstove, child access to unsafe cabinets with medications, cleaning liquids or fertilisers.

The multivariate model for injuries among children aged $<5$ years again demonstrated the protective effects of having older children in the household (eg, three older children in the household OR $0.26,95 \%$ CI 0.13 to 0.54 ; one older child is reference), living in owned home (OR $0.52,95 \% \mathrm{CI} 0.30$ to 0.89 ) and cooking outside of the home (OR $0.25,95 \%$ CI 0.13 to 0.49 ) (table 6).

\section{DISCUSSION}

This study aimed to describe the epidemiology of household injuries among children in rural Ghana and characterise household risk factors in an effort to identify prevention targets. The results offer several important findings. First, moderate and worse injuries occurred frequently in rural Ghana. Second, as in high-income countries, toddler-aged children were at particular risk of household injury, which was reduced when older children also lived in the home. Third, perceived common modifiable risk factors (eg, uncompleted housing, use of biomass fuels in open fires, low cookstoves, absence of secured cabinets for hazardous substances) were not associated with an increase in household injuries. Lastly, potential separations of children from cookstoves and cooking arrangements (eg, cooking outside of the home, having multiple rooms in the home) suggest that child barriers may be useful interventions in households that cook within the home or only have one room. Regardless, additional work is required to identify useful prevention targets for childhood injuries in LMICs.

Population-based studies on injuries in sub-Saharan Africa have demonstrated non-age-adjusted incidence rates that range from 32 to 760 per 1000 person-years. ${ }^{232426}$ 
Table 2 Caregiver, child and injury characteristics in Amakom subdistrict, Ghana

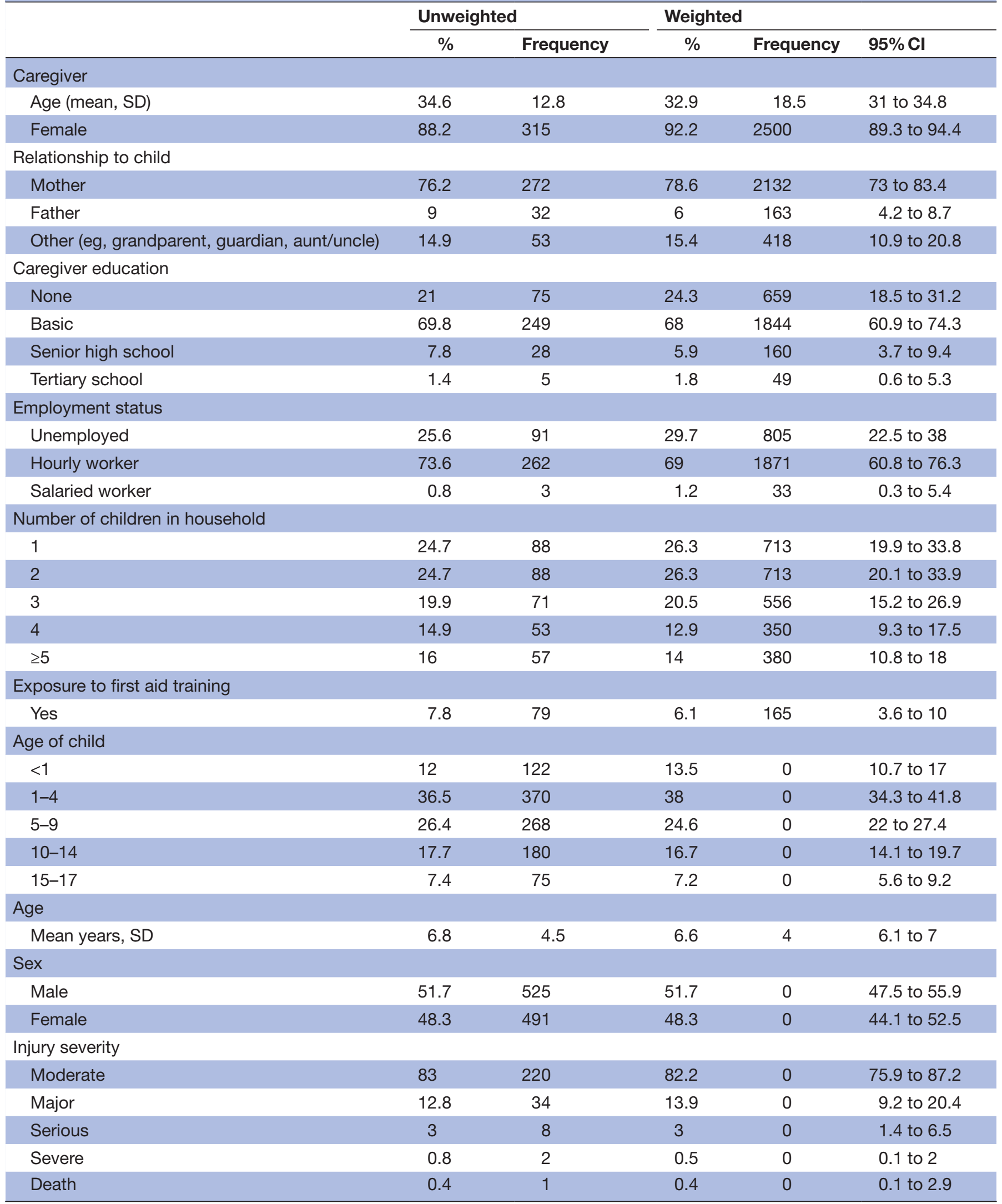

A study of urban childhood injuries in Ghana reported an incidence rate of moderate or worse injuries of 593 per 1000 child-years, which is only slightly higher than the rate we found in this rural population (542 injuries per 1000 child-years). ${ }^{17}$ For comparison, the incidence rate of childhood injury in Ghana is about 10 times higher 
Table 3 Weighted incidence of household injures by age group in Amakom subdistrict, Ghana

\begin{tabular}{|c|c|c|c|c|c|c|c|c|c|}
\hline & $<1$ year & $1-4$ years & 4-9 years & $\begin{array}{l}10-14 \\
\text { years }\end{array}$ & $\begin{array}{l}15-17 \\
\text { years }\end{array}$ & \multirow[b]{2}{*}{$P$ value } & \multirow[b]{2}{*}{$\begin{array}{l}\% \text { of } \\
\text { injuries }\end{array}$} & \multirow{2}{*}{$\begin{array}{l}\text { Injuries } \\
\text { within } 6 \\
\text { months \# }\end{array}$} & \multirow{2}{*}{$\begin{array}{l}\text { Incidence } \\
\text { rate per } \\
1000 \text { child- } \\
\text { years }\end{array}$} \\
\hline & $\begin{array}{l}\% \text { of } \\
760\end{array}$ & $\begin{array}{l}\% \text { of } \\
3019\end{array}$ & $\begin{array}{l}\% \text { of } \\
6911\end{array}$ & $\%$ of 2089 & $\%$ of 1253 & & & & \\
\hline \multicolumn{10}{|l|}{ Mechanism } \\
\hline Fall & 11.8 & 21.8 & 8.5 & 5.7 & 2 & $<0.01$ & 37.2 & 2058 & 210.9 \\
\hline Laceration & 1.7 & 8.9 & 5.8 & 4.9 & 7.7 & 0.01 & 24.3 & 1342 & 125.6 \\
\hline Burn & 2.4 & 6.4 & 2.2 & 1.5 & 3.8 & 0.01 & 12.4 & 683 & 63.1 \\
\hline Falling object & 0 & 0.3 & 1.4 & 0 & 0 & 0.87 & 1.7 & 95 & 15.1 \\
\hline Violence & 1.7 & 5.6 & 3.1 & 3.1 & 1 & $<0.01$ & 12.3 & 679 & 67.5 \\
\hline Animal-related & 0 & 1 & 0 & 1.4 & 0 & 0.34 & 2.3 & 128 & 8.5 \\
\hline Near drowning & 0 & 0.3 & 0.3 & 0 & 0 & 0.87 & 0.5 & 30 & 4.1 \\
\hline Poisoning & 1.4 & 0.5 & 0.8 & 0 & 0 & 0.42 & 1.6 & 86 & 11.5 \\
\hline Electric shock & 0 & 0.6 & 0 & 2 & 0 & 0.16 & 2.6 & 145 & 8.5 \\
\hline Suffocation & 1.5 & 0.4 & 0 & 0 & 0 & $<0.01$ & 0.7 & 36 & 3.3 \\
\hline Motor vehicle & 0 & 0.1 & 1.7 & 0.9 & 2.4 & 0.11 & 4.4 & 244 & 24.1 \\
\hline Total & 20.5 & 45.9 & 23.8 & 19.5 & 16.9 & $<0.01$ & 100 & 5526 & 542.3 \\
\hline
\end{tabular}

than that in the USA (52.6 per 1000 child-years). ${ }^{27} 28$ In accordance with previous published reports on the epidemiological differences between urban and rural injuries in Ghana and elsewhere, this rural population had a somewhat lower incidence rate of injury than their urban counterparts. ${ }^{17} 1829$ In both the urban and this rural population in Ghana, falls, lacerations and burns were the predominant injury mechanisms. However, motor vehicle-related injuries were twice as common in the urban population. The large number of injuries that occur in both urban and rural Ghana demand a coordinated prevention strategy and a well-organised trauma care system that are tailored to the epidemiological differences between urban and rural populations. Reports that define and identify injuries and prevention opportunities are requisite to developing and testing prevention interventions and adopting a coordinated prevention strategy specific to population differences. ${ }^{11}$

Toddler-aged children who are newly mobile and uninhibited are the most susceptible to household injuries. ${ }^{3}$ In households and communities without sufficient supervision of toddlers (eg, no daycare, multiple children per household, stressors of poverty) and before a child enters formal schooling, there is a gap in child safety opportunities. However, there are multiple examples of opportunities to mitigate the risks to which this age group is exposed that align with the six channels of childhood injury prevention: (i) legislation and regulation, (ii)

Table 4 Weighted incidence of household injures by gender in Amakom subdistrict, Ghana

\begin{tabular}{|c|c|c|c|c|c|}
\hline & $\begin{array}{l}\text { Male } \\
\% \text { of } 7016\end{array}$ & $\begin{array}{l}\text { Incidence rate per } \\
1000 \text { male child-years }\end{array}$ & $\begin{array}{l}\text { Female } \\
\% \text { of } 7016\end{array}$ & $\begin{array}{l}\text { Incidence rate per } 1000 \\
\text { female child-years }\end{array}$ & $P$ value \\
\hline \multicolumn{6}{|l|}{ Mechanism } \\
\hline Fall & 14.5 & 290 & 11 & 220 & 0.46 \\
\hline Laceration & 7 & 140 & 5.7 & 114 & 0.4 \\
\hline Burn & 3.5 & 70 & 4.2 & 84 & 0.39 \\
\hline Falling object & 0 & 0 & 0.3 & 6 & 0.14 \\
\hline Violence & 4 & 80 & 3.3 & 66 & 0.54 \\
\hline Animal-related & 1.1 & 22 & 0 & 0 & 0.05 \\
\hline Near drowning & 0 & 0 & 0.4 & 8 & 0.14 \\
\hline Poisoning & 0.6 & 11.4 & 0.6 & 12.2 & 0.93 \\
\hline Electric shock & 0.9 & 18 & 0.2 & 4.1 & 0.12 \\
\hline Suffocation & 0.4 & 8 & 0.3 & 6 & 0.35 \\
\hline Motor vehicle injury & 1 & 20 & 0.6 & 12 & 0.54 \\
\hline Total & 33 & 659 & 26.6 & 532 & 0.25 \\
\hline
\end{tabular}


Table 5 Factors associated with household injury risk among children age $<18$ years in Amakom subdistrict, Ghana

Univariate model

Crude OR P value $(95 \% \mathrm{Cl})$

\section{Caregiver age}

Age (years)

Relationship with child

Mother (ref)

$\begin{array}{llll}\text { Father } & 0.81 & 0.39 & 0.50 \text { to } 1.31 \\ \text { Other } & 0.89 & 0.6 & 0.59 \text { to } 1.35\end{array}$

Caregiver education

None (ref)

$\begin{array}{llll}\text { Basic } & 1.40 & 0.05 & 1 \text { to } 1.99 \\ \text { Senior high } & 1.79 & 0.05 & 1.01 \text { to } 3.18 \\ \text { Tertiary } & 0.47 & 0.48 & 0.06 \text { to } 3.81\end{array}$

Employment status

Unemployed (ref)

Hourly worker

0.93

Salaried worker

$0.91 \quad 0.82 \quad 0.62$ to 1.52

Number of children $<5$ years in household

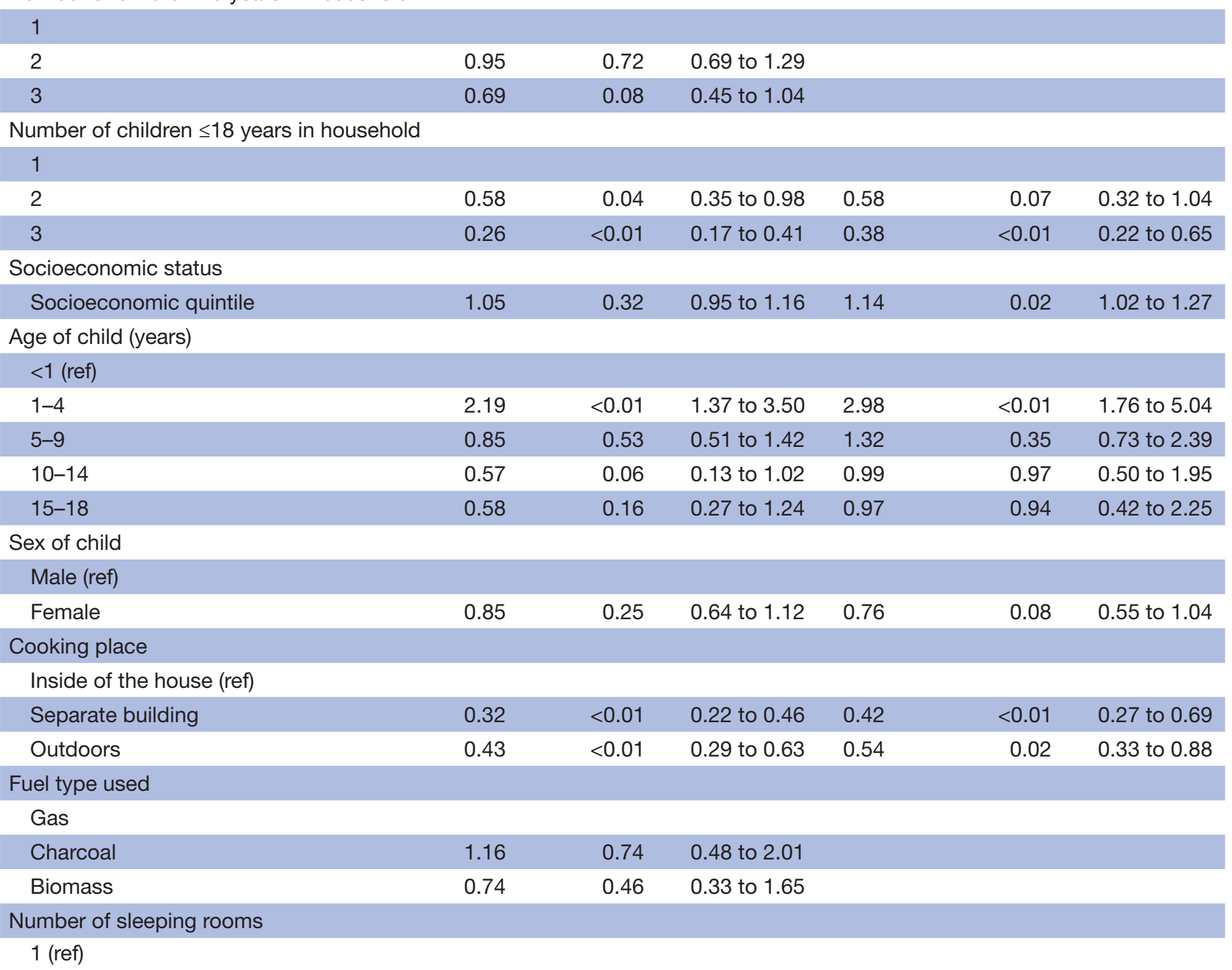

Continued

Multivariate model

Adjusted OR P value $(95 \% \mathrm{Cl})$

$0.99 \quad 0.16 \quad 0.98$ to 1


Table 5 Continued

\begin{tabular}{|c|c|c|c|c|c|c|}
\hline & \multicolumn{3}{|c|}{ Univariate model } & \multicolumn{3}{|c|}{ Multivariate model } \\
\hline & Crude OR & $P$ value & $(95 \% \mathrm{Cl})$ & Adjusted OR & $P$ value & $(95 \% \mathrm{Cl})$ \\
\hline 2 & 0.70 & 0.03 & 0.51 to 0.97 & 0.95 & 0.65 & 0.65 to 1.38 \\
\hline \multicolumn{7}{|l|}{ Accommodation } \\
\hline \multicolumn{7}{|l|}{ Rented room or hallway (ref) } \\
\hline Uncompleted accommodation & 1.23 & 0.41 & 0.75 to 2.03 & 1.72 & 0.05 & 1 to 3.01 \\
\hline Owned home & 0.76 & 0.16 & 0.52 to 1.12 & 0.67 & 0.07 & 0.43 to 1.03 \\
\hline \multicolumn{7}{|l|}{ Cabinet for hazardous substances } \\
\hline \multicolumn{7}{|l|}{ No (ref) } \\
\hline
\end{tabular}

ref, reference.

product modification, (iii) environmental modification, (iv) supportive home visits, (v) promotion of safety devices and (vi) caregiver education. ${ }^{3}$ As example of a safety intervention bundle, 211 households in South Africa were randomised to supportive home visits to identify and mitigate hazards for falls, burns and poisonings. ${ }^{30}$ Community members were recruited and trained as supportive visitors who engaged with caregivers at four intervention visits that were conducted over 3 months. During the visits the supportive visitors provided education, safety devices and an implicit accountability strategy. After the intervention, there was a significant reduction in hazards associated with cookstove-related and cooking appliancerelated injuries and poisoning. Changes in burn and fall injury hazards were less significant. A similar trial of a bundle of home safety interventions (eg, supportive visits, assessment of hazards and maternal practices, provision of safety items) among marginalised households with toddlers in rural USA reported an increase in maternal self-efficacy for household injury control practices in the experimental group. ${ }^{30} \mathrm{~A}$ randomised controlled trial of a drowning prevention bundle using predominantly mobile technology for parents with children aged $<5$ years in Bangladesh is currently enrolling. ${ }^{31}$ Among the components of the bundle is a series of weekly text messages that reinforce potentially important drowning prevention strategies, including reducing or eliminating time that children are unsupervised. Given that we found that the presence of older children in the household was a protective factor, efforts to improve supervision of younger children might be a research topic to pursue further and a potential prevention strategy to consider. Although not conclusive, initiatives such as provision of playpens and creation of community creches have shown promise in reducing childhood injuries in LMICs. ${ }^{32} 33$

Common targets for interventions in high-income countries and perceived targets in many communities in LMICs (eg, uncompleted housing, biomass fuels in open fires, low cookstoves, absence of secured cabinets for hazardous substances) were either not present or not associated with injuries in this study. However, potential separations of children from cooking arrangements (eg, cooking outside of the home, having multiple rooms in the home) suggest that child barriers may be useful interventions in households that cook within the home or only have one room. Although there have been a number of proposed interventions to prevent falls (eg, safer designs and regulations for railings, incorporation of soft bases around playground equipment), burns (eg, provision of stable paraffin lamps, subsidising improved cookstoves, installation of smoke alarms, regulations for flameretardant fabric), poisonings (eg, childproofing cabinets, regulations for packaging of hazardous substances), violence (eg, social engagement and academic enrichment programmes, anger management programmes) and road traffic injuries in neighbourhoods (eg, traffic calming structures, crosswalks), many of these are not universally applicable, particularly in rural areas of LMICs. Therefore, more work needs to be done to identify common modifiable risk factor and behaviours for successful injury prevention and control. Important first steps include collecting reliable estimates of the child injury burden. ${ }^{3}$

This study has several limitations deserving of discussion. First, the results were generated from caregiver responses to the survey. We did not triangulate responses with those from other members of the household or independently verify them with direct observation. However, the validity of caregiver responses when approached by trained enumerators with validated surveys has been confirmed by multiple reports, including several from Ghana. ${ }^{1723} 34$ Second, the findings are subject to some degree of recall bias. We used a recall period of 6 months to mitigate the risk of bias given that a study from the same region in Ghana determined that a 6-month recall period resulted in a $75 \%$ decrease in reporting of minor 
Table 6 Factors associated with household injury risk among children age $<5$ years in Amakom subdistrict, Ghana

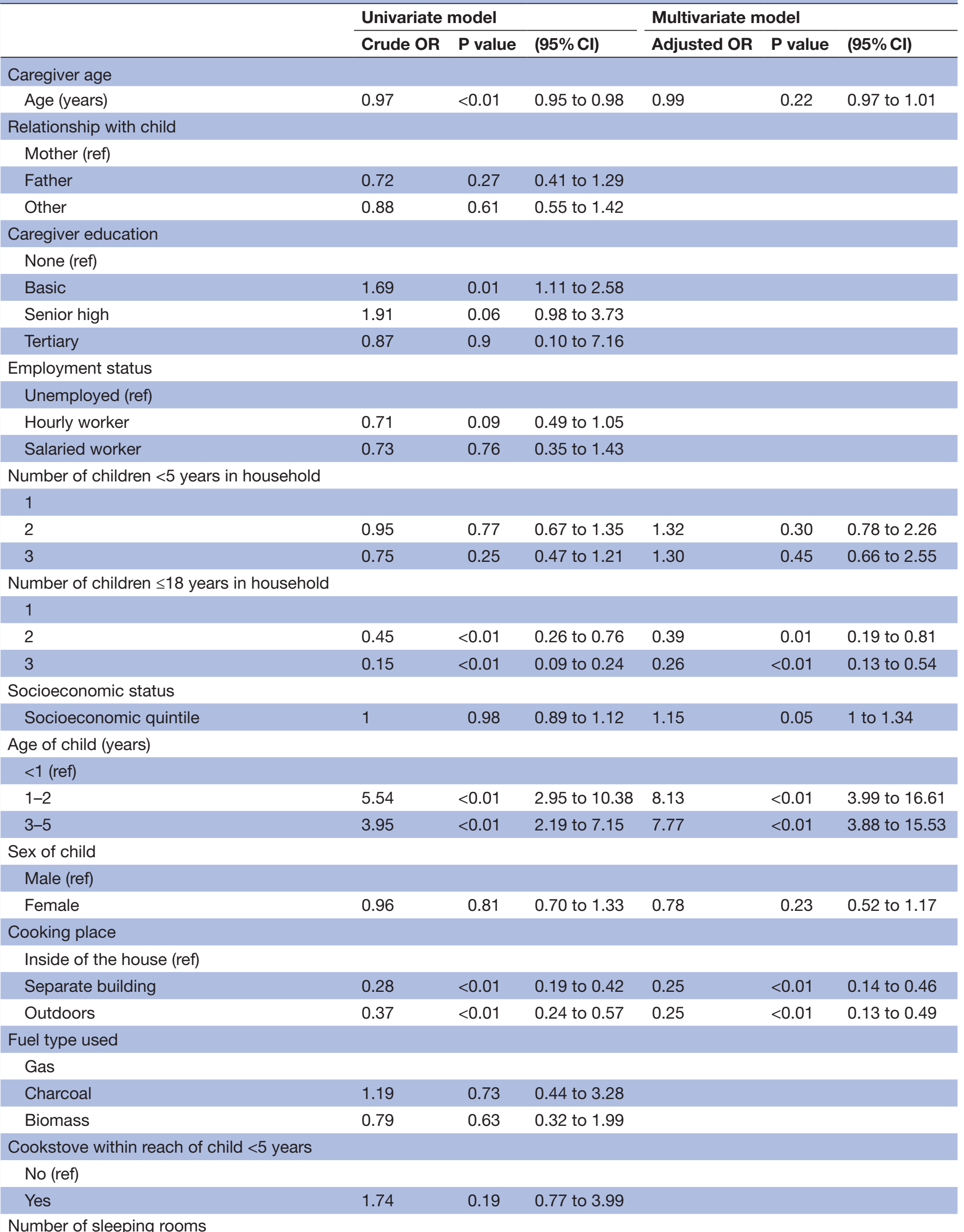




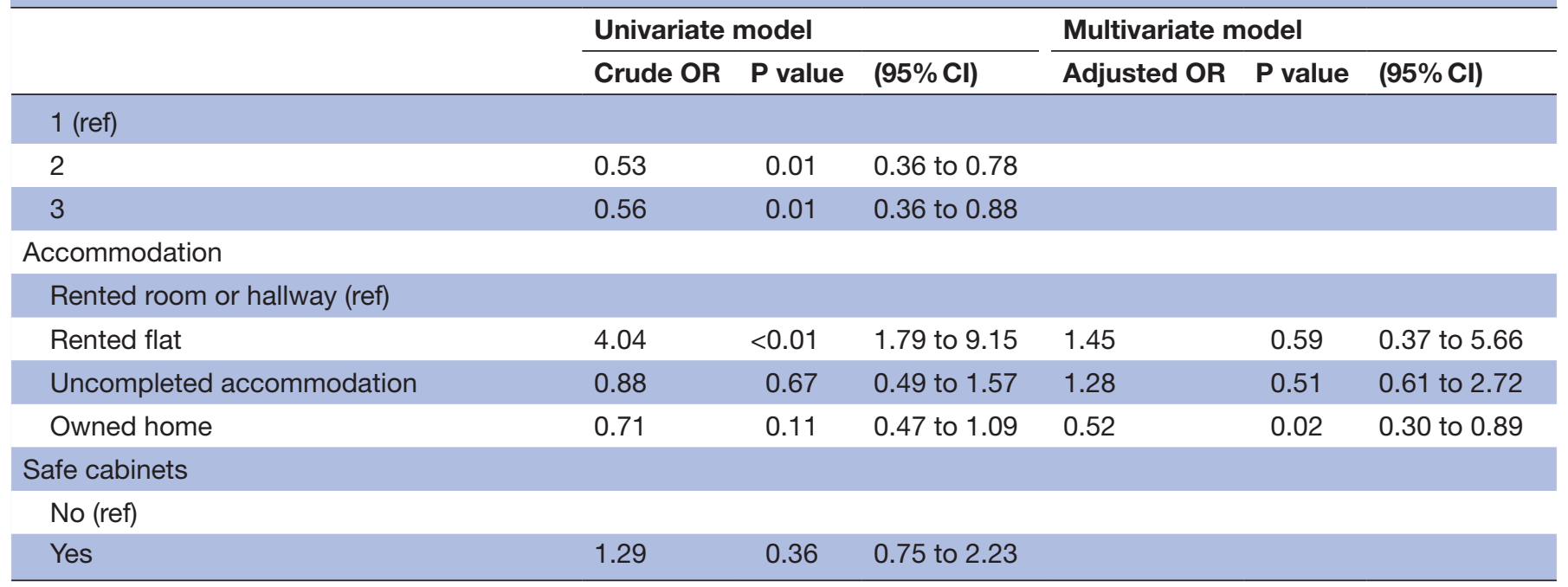

ref, reference.

injuries, $40 \%$ decrease in reporting of moderate injuries and no change in reporting of major injuries compared with a 1-month recall period. ${ }^{23}$ Third, the findings are also subject to caregiver social response bias. Social response bias may explain why there were very few injuries reported by caregivers that resulted in permanent disability or death. Next, only information on injuries that occurred within 200 metres of the home were recorded in order to allow apt comparison to other reports of household injury in Ghana and elsewhere. ${ }^{29}$ Lastly, this study was cross-sectional in design. Although there were some clear associations between injury and several risk factors, assumptions about causality should not be inferred to avoid inaccurate prevention initiative targeting.

\section{CONCLUSIONS}

Moderate and severe childhood injuries were frequent in rural Ghana, and almost as frequent as among their urban peers. ${ }^{29}$ As in high-income countries, toddler-aged children were at particular risk of household injury, which was reduced when older children also lived in the home. Given that the presence of older children in the household was a protective factor, efforts to improve supervision of younger children might be a research topic to pursue further and a potential prevention strategy to consider.

Perceived common modifiable risk factors (eg, uncompleted housing, use of biomass fuels in open fires, low cookstoves, absence of secured cabinets for hazardous substances) were not strongly associated with an increase in household injuries. Given the high burden of these injuries and availability of readily implementable and low-cost prevention strategies against home injuries, public health efforts in Ghana might reasonably focus on these initiatives. Likewise, it would also be reasonable to improve first aid knowledge of the caregivers and capabilities for trauma care at facilities that serve rural areas (eg, primary health posts, first-level hospitals).

\section{Author affiliations}

${ }^{1}$ Department of Surgery, Kwame Nkrumah University of Science and Technology, Kumasi, Ghana

${ }^{2}$ Directorate of Surgery, Komfo Anokye Teaching Hospital, Kumasi, Ghana ${ }^{3}$ Department of Surgery, University of Washington, Seattle, Washington, USA ${ }^{4}$ Global Injury Control Section, Harborview Injury Prevention \& Research Center, Seattle, Washington, USA

${ }^{5}$ Department of Community Health, Kwame Nkrumah University of Science and Technology, Kumasi, Ghana

${ }^{6}$ Kwame Nkrumah University of Science and Technology, Kumais, Ghana

${ }^{7}$ Surgery, University of Washington, Seattle, Washington, USA

Contributors AG, BTS, EO, PD and CM designed the study. AG, BTS, E0 and $\mathrm{KM}$ collected, managed and analysed the data. All coauthors contributed to the interpretation of the findings and drafting of the manuscript. All coauthors approved the final version for submission.

Funding This study was funded by grants D43-TW007267 and R25-TW009345 from the Fogarty International Center, US National Institutes of Health.

Competing interests None declared.

Patient and public involvement Patients and/or the public were not involved in the design, or conduct, or reporting, or dissemination plans of this research.

Patient consent for publication Not required.

Ethics approval Approval for the study was provided by the ethical review committee of the Kwame Nkrumah University of Science and Technology (AP/589/17) and the University of Washington Institutional Review Board. All data were anonymously recorded by consenting caregivers.

Provenance and peer review Not commissioned; externally peer reviewed.

Data availability statement Data are available upon reasonable request. All data relevant to the study are included in the article or uploaded as supplementary information. There are no additional data. Data will be provided after reasonable request to corresponding author.

Open access This is an open access article distributed in accordance with the Creative Commons Attribution Non Commercial (CC BY-NC 4.0) license, which permits others to distribute, remix, adapt, build upon this work noncommercially, and license their derivative works on different terms, provided the original work is properly cited, appropriate credit is given, any changes made indicated, and the use is non-commercial. See: http://creativecommons.org/ licenses/by-nc/4.0/. 
ORCID iD

Barclay T Stewart http://orcid.org/0000-0002-8099-9218

\section{REFERENCES}

1 Haagsma JA, Graetz N, Bolliger I, et al. The global burden of injury: incidence, mortality, disability-adjusted life years and time trends from the global burden of disease study 2013. Injury Prevention 2016;22:3-18.

2 Mock C, Abantanga F, Goosen J, et al. Strengthening care of injured children globally. Bull World Health Organ 2009;87:382-9.

3 Peden M, Oyegbite K, Ozanne-Smith J. World report on child injury prevention. Geneva, Switzerland: World Health Organization, 2008.

4 Albertyn R, Bickler SW, Rode H. Paediatric burn injuries in Sub Saharan Africa--an overview. Burns 2006;32:605-12.

5 Gyedu A, Mock C, Nakua E, et al. Pediatric first aid practices in Ghana: a population-based survey. World J Surg 2015;39:1859-66.

6 Ankomah J, Stewart BT, Oppong-Nketia V, et al. Strategic assessment of the availability of pediatric trauma care equipment, technology and supplies in Ghana. J Pediatr Surg 2015;50:1922-7.

7 Forjuoh SN, Guyer B, Smith GS. Childhood burns in Ghana: epidemiological characteristics and home-based treatment. Burns 1995;21:24-8.

8 Chandran A, Hyder AA, Peek-Asa C. The global burden of unintentional injuries and an agenda for progress. Epidemiol Rev 2010;32:110-20.

9 Dowswell T, Towner EM, Simpson G, et al. Preventing childhood unintentional injuries--what works? A literature review. Inj Prev 1996;2:140-9.

10 Harvey A, Towner E, Peden M, et al. Injury prevention and the attainment of child and adolescent health. Bull World Health Organ 2009;87:390-4

11 Sleet DA. The global challenge of child injury prevention. Int $J$ Environ Res Public Health 2018;15:1921.

12 Haagsma JA, Graetz N, Bolliger I, et al. The global burden of injury: incidence, mortality, disability-adjusted life years and time trends from the global burden of disease study 2013. Inj Prev 2016;22:3-18.

13 Cinnamon J, Schuurman N. Injury surveillance in low-resource settings using Geospatial and social web technologies. Int J Health Geogr 2010;9:25.

14 Mock C, Quansah R, Krishnan R, et al. Strengthening the prevention and care of injuries worldwide. Lancet 2004;363:2172-9.

15 Groen RS, Samai M, Stewart K-A, et al. Untreated surgical conditions in Sierra Leone: a cluster randomised, cross-sectional, countrywide survey. Lancet 2012;380:1082-7.

16 Petroze RT, Joharifard S, Groen RS, et al. Injury, disability and access to care in Rwanda: results of a nationwide cross-sectional population study. World J Surg 2015;39:62-9.

17 Gyedu A, Nakua EK, Otupiri E, et al. Incidence, characteristics and risk factors for household and neighbourhood injury among young children in semiurban Ghana: a population-based household survey. Inj Prev 2015;21:e71-9.

18 Kobusingye O, Guwatudde D, Lett R. Injury patterns in rural and urban Uganda. Inj Prev 2001;7:46-50.

19 World Health Organization. Violence and injury prevention. Geneva, Switzerland, 2015. http://www.who.int/violence_injury_prevention/en/

20 Ghana Washington, DC; USA: the world bank group, 2015. Available: http://data.worldbank.org/country/ghana

21 Gyedu A, Stewart B, Mock C, et al. Prevalence of preventable household risk factors for childhood burn injury in semi-urban Ghana: a population-based survey. Burns 2016;42:633-8.

22 Ghana Statistical Service. 2010 Ghana population and housing census. Accra, Ghana, 2014.

23 Mock C, Acheampong F, Adjei S, et al. The effect of recall on estimation of incidence rates for injury in Ghana. Int J Epidemiol 1999;28:750-5

24 Mock CN, Abantanga F, Cummings P, et al. Incidence and outcome of injury in Ghana: a community-based survey. Bull World Health Organ 1999;77:955-64.

25 Michael Linnan LVA, Cuong PV, Rahman F. Child mortality and injury in Asia: survey methods (Contract No.: IWP-2007-05. Geneva, Switzerland: UNICEF Innocenti Research Centre, 2007.

26 Moshiro C, Heuch I, Astrøm AN, et al. Effect of recall on estimation of non-fatal injury rates: a community based study in Tanzania. Inj Prev 2005;11:48-52.

27 Nagaraja J, Menkedick J, Phelan KJ, et al. Deaths from residential injuries in US children and adolescents, 1985-1997. Pediatrics 2005;116:454-61.

28 Phelan KJ, Khoury J, Kalkwarf H. Residential injuries in U.S. children and adolescents. Public health reports 2005;120:63-70.

29 Stewart B, Gyedu A, Otupiri E, et al. Comparison of childhood household injuries and risk factors between urban and rural communities in Ghana: a cluster-randomized, population-based, survey to inform injury prevention research and programming. Injury 2021;52:1757-65.

30 Odendaal W, van Niekerk A, Jordaan E. The impact of a home visitation programme on household hazards associated with unintentional childhood injuries: a randomised controlled trial. Accident Analysis \& Prevention 2009;41:183-90.

31 Hossain M, Mani KKC, Sidik SM, et al. Randomized controlled trial on drowning prevention for parents with children aged below five years in Bangladesh: a study protocol. BMC Public Health 2015;15:484.

32 Mashreky SR, Rahman A, Svanström L, et al. Experience from community based childhood burn prevention programme in Bangladesh: implication for low resource setting. Burns 2011;37:770-5.

33 Callaghan JA, Hyder AA, Khan R, et al. Child supervision practices for drowning prevention in rural Bangladesh: a pilot study of supervision tools. J Epidemiol Community Health 2010;64:645-7.

34 Gupta S, Ranjit A, Shrestha R, et al. Surgical needs of Nepal: pilot study of population based survey in Pokhara, Nepal. World J Surg 2014;38:3041-6. 